\title{
Effect of a professional soccer match in skin temperature of the lower limbs: a case study
}

\author{
Alex de Andrade Fernandes ${ }^{1, *}$, Eduardo Mendonça Pimenta ${ }^{2}$, Danilo Gomes Moreira', Manuel Sillero-Quintana ${ }^{3}$, \\ João Carlos Bouzas Marins ${ }^{4}$, Rodrigo Figueiredo Morandi', Tane Kanope ${ }^{5}$, Emerson Silami Garcia ${ }^{6}$ \\ ${ }^{1}$ Federal Institute for Education, Science and Technology of Minas Gerais, Campus Ipatinga and Governador Valadares, Governador Valadares, Brazil \\ ${ }^{2}$ Department of Physical Education, Physiotherapy, and Occupational Therapy School, Federal University of Minas Gerais, Belo Horizonte, Brazil \\ ${ }^{3}$ Faculty of Physical Activity and Sport Sciences, Technical University of Madrid, Madrid, Spain \\ ${ }^{4}$ Department of Physical Education, Human Performance Laboratory, Federal University of Viçosa, Viçosa, Brazil \\ ${ }^{5}$ Medical and Physiology Department, Cruzeiro Esporte Clube, Belo Horizonte, Brazil \\ ${ }^{6}$ Department of Physical Education, Federal University of Maranhão, Maranhão, Brazil
}

The purpose of this study is to analyze the relationship between lower limbs skin temperature (Tsk) recorded by infrared thermography and creatine kinase (CK) response following an official soccer game. A professional soccer player, from the first division Brazilian League, defender, 27 years and $183 \mathrm{~cm}$ of height was analyzed. Measures of Tsk with a thermal camera and blood CK concentrations were obtained $24 \mathrm{hr}$ before (24H-PRE), 24 (24H-POST) and $48 \mathrm{hr}$ (48H-POST) after an official match. The results showed that CK values were $193 \mathrm{U} / \mathrm{L} 24 \mathrm{hr}$ before, rising to 1,083 U/L $24 \mathrm{hr}$ after the game and $414 \mathrm{U} / \mathrm{L} 48 \mathrm{hr}$ after the game. Anterior thigh Tsk was $31.5^{\circ} \mathrm{C}, 33.8^{\circ} \mathrm{C}$, and $31.8^{\circ} \mathrm{C}$ in the moments $24 \mathrm{H}-\mathrm{PRE}$, 24H-POST, and 48H-POST, respectively. Similarly, anterior leg presented temperature of $31.2^{\circ} \mathrm{C}, 33.3^{\circ} \mathrm{C}$, and $31.5^{\circ} \mathrm{C}$ at the same moments. Qualita- tive analysis of the thermograms showed that whole lower limbs are much warmer $24 \mathrm{hr}$ after the match and certain areas as the right anterior thigh, the left anterior leg, both anterior ankles, and both posterior thighs have not fully recovered their initial Tsk $48 \mathrm{hr}$ after the match. The results of this study indicate that participation in a professional soccer match can lead to significant increases in Tsk values measured by IRT $24 \mathrm{hr}$ after the match. Considering this variable as an indicator of muscular damage, it could help in the process of training control, being part of an injury prevention program in professional soccer clubs.

Keywords: Infrared thermography, Skin temperature, Injury prevention, Soccer

\section{INTRODUCTION}

Participation in a soccer match results in a large number of microinjuries originated by the eccentric mechanical actions, generating muscle fibers ruptures, cell membrane damage, and sarcomeric degeneration (Hyldahl and Hubal, 2014; Kanda et al., 2013). Following this process, an acute local inflammatory response is triggered involving the release of different cytokines, migration of neutrophils to the trauma areas, and then releasing certain agents into the damaged fibers to attract macrophages that ingest and digest the dead tissue (Mohr et al., 2016; Walsh et al., 2011).

Increases in local tissue vascular activity following these inflam- matory processes have been reported (Paulsen et al., 2012). In fact, some signs are produced by the body in this acute inflammatory response such as: heat, redness, pain, and these are generally noted after soccer matches (Paulsen et al., 2012; Young et al., 2012). Moreover, due to the greater vascular activity and the heat increase generated by the exercised muscles, it has been suggested that skin temperature (Tsk) recorded by infrared thermography (IRT) on the exercised body regions could be a good indicator of muscle stress (Hildebrandt et al., 2010). Thus, considering that the development of injury prevention program in professional soccer players requires reliable and fast information to address the level muscle damage and its location, we analyzed the relationship be-
${ }^{*}$ Corresponding author: Alex de Andrade Fernandes

(iD) http://orcid.org/0000-0001-7087-8263

Federal Institute for Education, Sciences and Technology of Minas Gerais, Av. João Valentim Pascoal, s/n - Centro - Ipatinga - Minas Gerais, Brazil

Tel \& Fax: +55-31-3899-2076, E-mail: alex.andrade@ifmg.edu.br

Received: February 25, 2017 / Accepted: June 5, 2017
This is an Open Access article distributed under the terms of the Creative Commons Attribution Non-Commercial License (http://creativecommons.org/licenses/by-nc/4.0/) which permits unrestricted non-commercial use, distribution, and reproduction in any medium, provided the original work is properly cited. 
tween lower limbs Tsk variation recorded by IRT and creatine kinase $(\mathrm{CK})$ response following a soccer game. This analysis may help to understand the local thermal response after soccer match, expanding the view to the muscular damage response generated by matches, and helping to analyze exercise load.

\section{MATERIALS AND METHODS}

\section{Participant}

The analyzed athlete is a defender, with right dominant leg, nonsmoker, and member of a first division club of Brazilian Soccer League (age, 27 years; height, $183.0 \mathrm{~cm}$; percentage body fat, $10.8 \%$; body surface area, $1.92 \mathrm{~m}^{2}$; and $\dot{\mathrm{V}}_{2 \max }, 54,7 \mathrm{~mL} / \mathrm{min} / \mathrm{kg}$ ). Two weeks before the game, the participant underwent a medical examination in which he completed a health history questionnaire, and had his body weight, height, body fat, and $\dot{\mathrm{V}}_{2 \max }$ assessed. He participated in at least six training sessions per week (mean, 2 hr) and played at least one match per week. No recent history of febrile illness, muscle lesions, lower limb trauma, and metabolic diseases, and no consumption of performance-enhancing supplements and medications for at least 6 months before the study were reported. The volunteer was informed about the procedures at all stages of the study and signed an informed consent form prior to the start the study. This study was approved by the local Ethics Committee on Human Research (No. 50708915.6.0000.5149) of the BLINDED, which followed the principles outlined by the World Medical Assembly Declaration of Helsinki.

\section{Procedures}

The body mass in grams (anthropometric mechanical scale, Welmy, São Paulo, Brazil), height in centimeters (stadiometer, Welmy) and skinfolds (subscapular, triceps, pectoral, axillary, suprailiac, abdominal and thigh) in millimeters (Lange, Santa Cruz, CA, USA) were measured by a trained anthropometrist according to the recommendations of the International Society for the Advancement of Kinanthropometry (Marfell-Jones et al., 2006). The values of each fold were used to obtain the sum of the folds and to calculate the percentage of fat according to the equation proposed by Jackson and Pollock (1978). The body surface area was calculated from the body weight and height measurements, according to Du Bois and Du Bois (1989). The $\dot{\mathrm{V}}_{2 \max }$ was evaluated indirectly through the YoYo Endurance Test (level 2) (Bangsbo, 1994). This is specific test for soccer and intermittent sports (Krustrup et al., 2003), which the total distance traveled is positively related to athletes' aerobic capacity (Castagna et al., 2006).
The analyzed athlete participated in a full official match in a field with natural grass $(105 \mathrm{~m} \times 68 \mathrm{~m})$ which took place between 1,600 and $1,800 \mathrm{hr}$. The mean temperature and humidity during the game were $27^{\circ} \mathrm{C} 60 \%$ respectively, according to Brazilian National Institute of Meteorology (www.inmet.gov.br). In the day before and 2 days after the game, no physical exercise was performed. However, on the game day, a normal soccer warm-up was performed before and a normal cool-down period after.

Data collection was performed in three different moments: (a) $24 \mathrm{hr}$ before an official match of the First Division Brazilian League, (b) $24 \mathrm{hr}$ after the start of the match, and (c) $48 \mathrm{hr}$ after the match. At all times, CK data and thermal images were collected at the same time of the day $(1,600 \mathrm{hr})$.

Thermograms were collected in a room properly equipped with artificial fluorescent lamps, and the environmental temperature was maintained through a heating/cooling air conditioner (Hiwall Split, Komeco, São Paulo, Brazil). The average temperature remained at $24.2^{\circ} \mathrm{C} \pm 0.5^{\circ} \mathrm{C}$, and the relative humidity was $55.3 \% \pm 3.5 \%$; both measures were recorded with a digital weather station and anemometer (AD-250, Instrutherm, São Paulo,

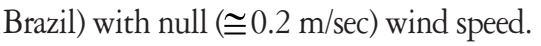

The participant was previously instructed to avoid alcohol beverages, caffeine, large meals, ointments, cosmetics, and showering for $4 \mathrm{hr}$ before the assessment. He was positioned away from any source of infrared radiation (e.g., electronic devices, lightning) or airflow (e.g., under an air conditioning unit). After remained standing for $10 \mathrm{~min}$ with the legs uncovered in the test room for acclimation (Marins et al., 2014b), he was positioned in an anatomical position at 3-m distance in order the cover $75 \%$ of the region of interest within the image. The camera was turned on 30 min prior to the test to allow sensor stabilization following the manufacturer's guidelines and the images were recorded perpendicularly to the region of interest. An infrared imager (FLIR T420, FLIR Systems Inc., Wilsonville, OR, USA) with a measurement range from $-20^{\circ} \mathrm{C}$ to $+120^{\circ} \mathrm{C}, 2 \%$ accuracy, sensitivity $\leq 0.05^{\circ} \mathrm{C}$, IR spectral band of 7.5 to $13 \mu$, refresh rate of $60 \mathrm{~Hz}$, auto-focus and a resolution of $320 \times 240$ pixels was used to obtain the thermograms.

For the collection of two thermograms (anterior and posterior regions of the body), body regions of interest (ROI) were selected manually in a specific software (FLIR Tools, FLIR Systems Inc.), with rectangles of $10-\mathrm{cm}$ width $\times 20-\mathrm{cm}$ height on the thighs (right and left) and 7-cm width $\times 19-\mathrm{cm}$ height on the legs (right and left), as reported in previous studies (Marins et al., 2014a; Marins et al., 2014b). The emissivity value adopted for human 
skin was 0.98 and the reflected temperature was set as $23^{\circ} \mathrm{C}$ in the thermal camera.

In order to determine the enzymatic concentration of $\mathrm{CK}$ in plasma, the fingertips of the player was cleaned with $95 \%$ ethanol and dried with cotton. A lancet was used with an automatic puncture trigger and $32 \mu \mathrm{L}$ of capillary blood were collected into a heparinized capillary tube $\left(\right.$ Reflotron $\left.^{\circledR}\right)$ and immediately pipetted into a reactive strip of $\mathrm{CK}$ (Reflotron ${ }^{\circledR}$ ) and inserted into the Reflotron Analyser (Reflotron, Zürich, Switzerland).

\section{Data analysis}

The analysis of the images considered both the mean temperature values of the selected areas of interest (quantitative analysis) and the visual analysis considering the visible heat points in the thermogram (qualitative analysis). All theses analyzes were carried out by a trained thermographer (level 1 accredited by Infrared Training Center).

\section{RESULTS}

Figs. 1 and 2 present the thermal images recorded at the different moments in anterior and posterior views respectively.

Table 1 shows the mean Tsk values of the right and left thighs and legs (right and left) in the anterior and posterior views at the

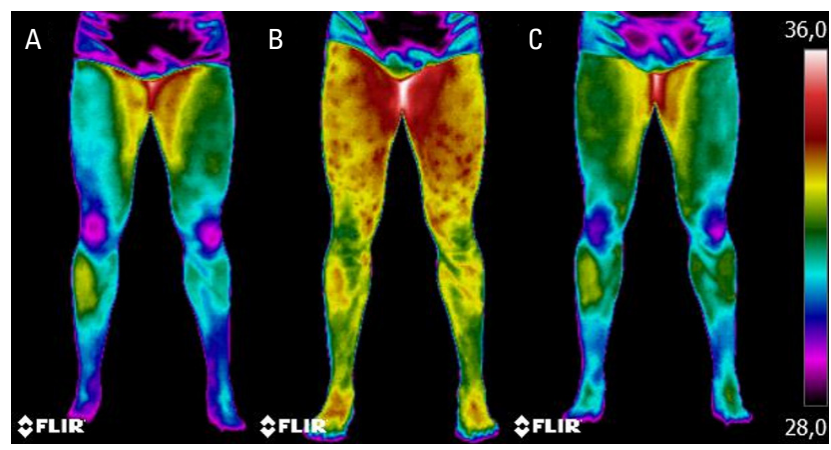

Fig. 1. Thermograms of the anterior views: (A) $24 \mathrm{hr}$ before the match, (B) $24 \mathrm{hr}$ after starting the match, and (C) $48 \mathrm{hr}$ after starting the match. different moments analyzed, as well as the delta $(\Delta)$ of the Tsk of the first moment compared to the second moment $(\Delta$ PRE-24) and of the first moment compared to the third moment ( $\triangle$ PRE48). The $\mathrm{CK}$ values obtained were $193 \mathrm{U} / \mathrm{L} 24 \mathrm{hr}$ before, rising to $1,083 \mathrm{U} / \mathrm{L} 24 \mathrm{hr}$ after the game and $414 \mathrm{U} / \mathrm{L} 48 \mathrm{hr}$ after the game.

On the other hand, considering that the thermal range of the thermograms were fixed between $28^{\circ} \mathrm{C}$ and $36^{\circ} \mathrm{C}$, using qualitative analysis of the image it is possible to observe clearly how the whole lower limbs are much warmer $24 \mathrm{hr}$ after the match and certain areas as the right anterior thigh, the left anterior leg, both anterior ankles, and both posterior thighs have not fully recovered their initial Tsk $48 \mathrm{hr}$ after the match. Additionally, both posterior legs are colder than in the initial thermogram $48 \mathrm{hr}$ after the match.

\section{DISCUSSION}

The results of the case study indicate that participation in a professional soccer match may result in significant increases in Tsk values recorded $24 \mathrm{hr}$ after the game compared to the prematch data collected $24 \mathrm{hr}$ before the match. In addition, results also indicate that Tsk turns to values close to those recorded before the match $48 \mathrm{hr}$ after its completion.

We can hypothesize that participation in a soccer match results in a marked number of muscular microinjuries that could be

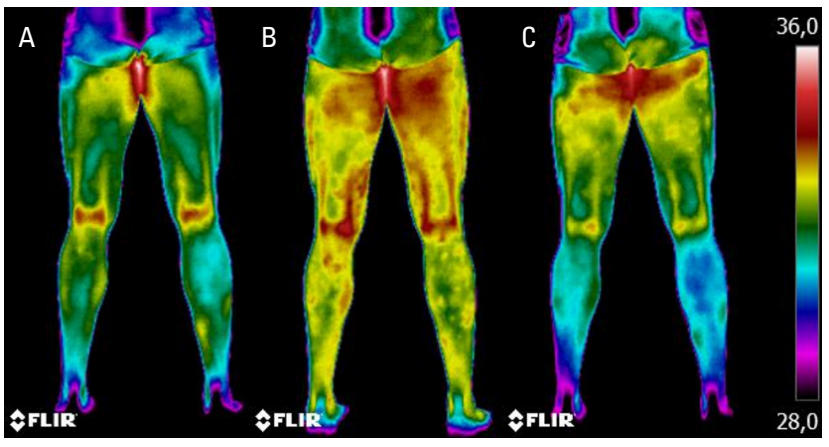

Fig. 2. Thermograms of the posterior views: (A) $24 \mathrm{hr}$ before the match, (B) 24 hrafter starting the match, and (C) $48 \mathrm{hr}$ after starting the match.

Table 1. Mean skin temperature of the thighs (right and left) and legs (right and left) in the anterior and posterior view at the different moments analyzed, as well as the delta $(\Delta)$ of the initial moment compared with the second moment ( $\triangle$ PRE-24) and with the third moment ( $\Delta$ PRE-48)

\begin{tabular}{lccccc}
\hline & $24 \mathrm{H}-\mathrm{PRE}$ & $24 \mathrm{H}-\mathrm{POST}$ & $\Delta$ PRE-24 & $48 \mathrm{H}-\mathrm{POST}$ & $\Delta$ PRE-48 \\
\hline Thighs anterior & $31.5^{\circ} \mathrm{C}$ & $33.8^{\circ} \mathrm{C}$ & $+2.3^{\circ} \mathrm{C}$ & $31.8^{\circ} \mathrm{C}$ & $+0.3^{\circ} \mathrm{C}$ \\
Legs anterior & $31.2^{\circ} \mathrm{C}$ & $33.3^{\circ} \mathrm{C}$ & $+2.1^{\circ} \mathrm{C}$ & $31.5^{\circ} \mathrm{C}$ & $+0.2^{\circ} \mathrm{C}$ \\
Thighs posterior & $32.1^{\circ} \mathrm{C}$ & $34.6^{\circ} \mathrm{C}$ & $+2.5^{\circ} \mathrm{C}$ & $32.5^{\circ} \mathrm{C}$ & $+0.4^{\circ} \mathrm{C}$ \\
Legs posterior & $31.0^{\circ} \mathrm{C}$ & $33.2^{\circ} \mathrm{C}$ & $+2.2^{\circ} \mathrm{C}$ & $31.7^{\circ} \mathrm{C}$ & $+0.7^{\circ} \mathrm{C}$
\end{tabular}

24H-PRE, 24-hr prematch; 24H-POST, 24-hr postmatch; 48H-POST, 48-hr postmatch. 
linked to an acute inflammatory local response, given the high value of $\mathrm{CK}$ and Tsk founded. The analysis $24 \mathrm{hr}$ after the match showed a CK value of 1,083 U/L which is considered extremely high for male athletes (Mougios, 2007) and increments between $2.1^{\circ} \mathrm{C}$ and $2.5^{\circ} \mathrm{C}$ in all the considered ROI. In addition, the evolution of the Tsk appears to be similar to $\mathrm{CK}$, with a increase $24 \mathrm{hr}$ after the match and returning to prematch levels $48 \mathrm{hr}$ after. These results indicate the acute response and the recovery process considering the conditions in term of sleeping, feeding, and resting.

The increment of the Tsk values for all the considered ROI in this study case were higher than $2.0^{\circ} \mathrm{C} 24 \mathrm{hr}$ after the game, reaching $2.5^{\circ} \mathrm{C}$ in the posterior region of the thighs. However, this appears to be a natural and normal condition for elite athletes after participating in an official soccer match. It is important to highlight that the studied athlete underwent medical clinical evaluation after the match and there was no evidence or complaint of injury, reinforcing the hypothesis that Tsk increases after the match was due to the inflammatory process (Mohr et al., 2016).

The images (Figs. 1, 2) show clearly that the adductor region, precisely one of the most susceptible to injury in soccer, presents the higher temperature $24 \mathrm{hr}$ after the match and the thigh present several high temperature spots that could be related with local muscle damage mainly in the anterior thighs and in the right posterior thigh. On the other hand, certain areas as the right anterior and posterior thigh, the left anterior leg and the anterior ankles did not recovered the baseline Tsk as in the rest of the ROI. It is also quite interesting that the posterior legs become colder than the reference values $48 \mathrm{hr}$ after the match. This could be an individual response of the athlete related to the personal adaption to allow a better recovery after the extreme effort performed during the match. Overloading those regions before the full recovery could generate an increased risk of injury to that player on those areas.

It is worth noting that unlike the $\mathrm{CK}$ analysis that presents a general idea of muscle damage, the thermogram can determine the locations where the microinjuries and inflammatory process are most acute after an intense training session or a match, and thus, the possible imbalances caused by the maximal exercise could be early detected. This point is crucial within an injury prevention program, which in the specific case of soccer may have a significant economic impact by preventing a player from having an injury.

Strategies for injury prevention in athletes require a broad understanding of physical effort effects and possible regions susceptible to injury. In this way, further studies with a higher number of athletes should be developed with the purpose of proving the indicatives pointed out in this case study, verifying the relationship between CK levels, as indicator of muscle damage, and Tsk recorded by IRT in different population groups.

The results of this study indicate that participation in a professional soccer match can lead to significant increases in Tsk values measured by IRT $24 \mathrm{hr}$ after the match. Considering this variable as an indicator of muscular damage, it could help in the process of training control, being part of an injury prevention program in professional soccer clubs.

\section{CONFLICT OF INTEREST}

No potential conflict of interest relevant to this article was reported.

\section{ACKNOWLEDGMENTS}

The authors of this article thank the following research funding agencies: Federal Institute for Education, Science and Technology of Minas Gerais (IFMG); Coordination for the Improvement of Higher Education Personnel (CAPES); Foundation for Research Support of the Minas Gerais State (FAPEMIG); National Council of Scientific and Technological Development (CNPq).

\section{REFERENCES}

Bangsbo J. Fitness training in football: a scientific approach. Bagsværd (Denmark): HO Storm; 1994.

Castagna C, Impellizzeri FM, Chamari K, Carlomagno D, Rampinini E. Aerobic fitness and yo-yo continuous and intermittent tests performances in soccer players: a correlation study. J Strength Cond Res 2006;20:320-325

Du Bois D, Du Bois EF. A formula to estimate the approximate surface area if height and weight be known. 1916. Nutrition 1989;5:303-311.

Hildebrandt C, Raschner C, Ammer K. An overview of recent application of medical infrared thermography in sports medicine in Austria. Sensors (Basel) 2010;10:4700-4715.

Hyldahl RD, Hubal MJ. Lengthening our perspective: morphological, cellular, and molecular responses to eccentric exercise. Muscle Nerve 2014;49:155-170.

Jackson AS, Pollock ML. Generalized equations for predicting body density of men. Br J Nutr 1978;40:497-504.

Kanda K, Sugama K, Hayashida H, Sakuma J, Kawakami Y, Miura S, Yoshioka H, Mori Y, Suzuki K. Eccentric exercise-induced delayed-onset muscle soreness and changes in markers of muscle damage and inflammation. Exerc Immunol Rev 2013;19:72-85. 
Krustrup P, Mohr M, Amstrup T, Rysgaard T, Johansen J, Steensberg A, et al. The yo-yo intermittent recovery test: physiological response, reliability, and validity. Med Sci Sports Exerc. 2003;35:697-705.

Marfell-Jones M, Olds TS, Stewart A, Carter L. International standards for anthropometric assessment, Potchefstroom (South Africa): International Society for the Advancement of Kinanthropometry; 2006.

Marins JC, Fernandes AA, Moreira DG, da Silva FS, Costa CM, Pimenta E, Sillero-Quintana M. Thermographic profile of soccer players' lower limb. Rev Andal Med Deporte 2014a;7:1-6.

Marins JC, Moreira DG, Cano SP, Sillero-Quintana M, Soares DD, Fernandes AA, Silva FS, Costa CM. Time required to stabilize thermographic images at rest. Infrared Phys Technol 2014b;65:30-35.

Mohr M, Draganidis D, Chatzinikolaou A, Barbero-Álvarez JC, Castagna C, Douroudos I, Avloniti A, Margeli A, Papassotiriou I, Flouris AD, Jamurtas AZ, Krustrup P, Fatouros IG. Muscle damage, inflammatory, immune and performance responses to three football games in 1 week in competitive male players. Eur J Appl Physiol 2016;116:179-193.

Mougios V. Reference intervals for serum creatine kinase in athletes. Br J Sports Med 2007;41:674-678.

Paulsen G, Mikkelsen UR, Raastad T, Peake JM. Leucocytes, cytokines and satellite cells: what role do they play in muscle damage and regeneration following eccentric exercise? Exerc Immunol Rev 2012;18: 42-97.

Walsh NP, Gleeson M, Shephard RJ, Gleeson M, Woods JA, Bishop NC, Fleshner M, Green C, Pedersen BK, Hoffman-Goetz L, Rogers CJ, Northoff H, Abbasi A, Simon P. Position statement. Part one: Immune function and exercise. Exerc Immunol Rev 2011;17:6-63.

Young WB, Hepner J, Robbins DW. Movement demands in Australian rules football as indicators of muscle damage. J Strength Cond Res 2012;26:492-496. 